\title{
A materialidade da crônica: dialética da vida ao rés-do-chão
}

\section{The materiality of the chronicle: dialetics of life at the ground floor}

\author{
William Moreno Boenavides ${ }^{1}$ (IFSC)
}

\begin{abstract}
Resumo: Interessa neste texto discutir a constituição do gênero crônica em perspectiva materialista. O debate se faz importante na medida em que tal modo de análise não tem imperado nas tentativas de estabelecimento dos traços constitutivos deste gênero. Como produto cultural, a crônica é marcada pelas contradições sociais e formais que permeiam seu meio e condições de produção. No transcurso do seu desenvolvimento no Brasil do século XIX, tensões históricas aí presentes migraram para sua própria constituição formal.
\end{abstract}

Palavras-chave: Crônica; Séc. XIX; Materialismo histórico; Dialética; Imprensa.

Abstract: This text is interested in discussing the constitution of the chronic gender in a materialistic perspective. The debate is important as this method of analysis has not prevailed in attempts to establish the constitutive features of this genre. As a cultural product, the chronicle is marked by social and formal contradictions that permeate its environment and production conditions. In the course of its development in 19th century Brazil, historical tensions present there migrated to its own formal constitution.

Keywords: Chronicle; 19th century; Historical materialism; Dialectic; Press.

"O malandro anda assim de viés" Chico Buarque, A volta do malandro

Num texto de 1980, que serviu de introdução a uma coletânea de crônicas destinadas ao público escolar, e que foi republicado em outros momentos pelo autor ${ }^{2}$,

\footnotetext{
${ }^{1}$ Professor do IFSC (Instituto Federal de Santa Catarina), campus Araranguá. Mestre e doutor em Literatura Brasileira pela Universidade Federal do Rio Grande do Sul.

${ }^{2}$ A primeira publicação desse texto de Candido serviu de introdução ao livro Para gostar de ler: crônicas. São Paulo: Ática, 1980 (Vol. 5). O livro reuniu crônicas de Carlos Drummond de Andrade, Rubem Braga, Fernando Sabino e Paulo Mendes Campos. Posteriormente, ele foi recolhido em um volume com textos de vários autores, todos voltados ao estudo da crônica.: A crônica: o gênero, sua fixação e suas transformações no Brasil. Campinas, SP: Editora da UNICAMP; Rio de Janeiro: Fundação Casa de Rui Barbosa, 1992. O texto de Candido nesse livro também cumpriu o papel de introdução ("À guisa de introdução" dizia a inscrição que acompanhava o título do seu artigo). No ano seguinte a essa publicação, integrou o livro de ensaios de Antonio Candido: Recortes. São Paulo: Companhia das Letras, 1993. Em todos os casos, o texto permaneceu rigorosamente o mesmo, incluindo apenas indicações em nota de rodapé sobre a coletânea da série "Para gostar de ler" que originou a primeira publicação (Cf. CANDIDO, 1980; 1992; 1993 e DANTAS, 2002, p. 28). Assim, se por um lado devemos considerar o fato de o texto ter sido produzido como introdução a uma coletânea escolar, não tendo, portanto, o caráter de estudo mais aprofundado que
} 


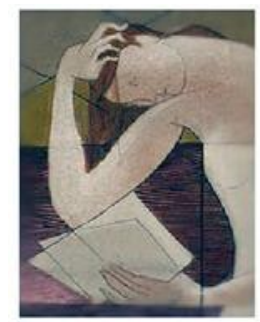

https://seer.ufrgs.br/NauLiteraria

Vol. 16, n. 22019

Dossiê Antonio Candido

Candido (1992, p. 13) situa a condição da crônica como "gênero menor", no sentido de que a literatura de uma dada nacionalidade não teria, só com cronistas, o "brilho universal dos grandes romancistas, dramaturgos e poetas", da mesma forma, não "se pensaria em atribuir o Prêmio Nobel a um cronista, por melhor que fosse". Note-se que o que é referido por Candido, nesse primeiro momento, para definir ou não a grandeza de um gênero são categorias abstratas, como "brilho universal" e os mecanismos institucionalizados de consagração, como o Prêmio Nobel. Contudo, o que impera no texto do autor não é uma visão pejorativa do gênero; ao contrário, ele comemora essa não grandiosidade da crônica, que possibilita que ela fique "perto de nós". Mesmo assim, num primeiro momento, o autor parece não a considerar propriamente literatura, já que vê na crônica um "caminho não apenas para vida, que ela serve de perto, mas para a literatura", mas essa visão vai se alterando no andamento do texto:

Por meio dos assuntos, da composição aparentemente solta, do ar de coisa sem necessidade que costuma assumir, ela se ajusta à sensibilidade de todo o dia. Principalmente porque elabora uma linguagem que fala de perto ao nosso modo de ser mais natural. Na sua despretensão, humaniza; e esta humanização lhe permite, como compensação sorrateira, recuperar com a outra mão uma certa profundidade de significado e um certo acabamento de forma, que de repente podem fazer dela uma inesperada embora discreta candidata à perfeição (CANDIDO, 1992, p. 13-14).

Essas aparentes despretensão e proximidade vão marcar o entendimento de Candido sobre a crônica em sentido mais geral. Diz ele: "vamos pensar um pouco na própria crônica como gênero. Lembrar, por exemplo, que o fato de ficar tão perto do dia a dia age como quebra do monumental e da ênfase" (CANDIDO, 1992, p. 14). O que seria bom, já que há "um problema" na "magnitude do assunto" e na "pompa da linguagem", pois “eles podem atuar como disfarce da realidade e até mesmo da verdade". Para o autor (CANDIDO, 1992, p. 14), "a literatura corre com frequência este risco, cujo resultado é quebrar no leitor a possibilidade de ver as coisas com retidão e pensar em consequência disto". Já a "crônica está sempre ajudando a estabelecer ou restabelecer a dimensão das coisas e das pessoas". Ela não oferece "um cenário excelso, numa revoada

outros trabalhos do autor possuem, por outro lado podemos considerá-lo uma visão pronta de Candido sobre o gênero, haja vista suas republicações e a ausência de comentários seus em contrário. 


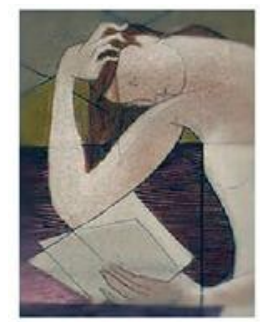

https://seer.ufrgs.br/NauLiteraria

Vol. 16, n. 22019

Dossiê Antonio Candido

de adjetivos e períodos candentes, pega o miúdo e mostra nele uma grandeza, uma beleza ou uma singularidade insuspeitadas".

Para Candido, esses traços positivos da crônica se devem a suas condições de produção, já que não foram feitas para o livro, mas para o jornal, sendo sua filha "e da era da máquina, onde tudo acaba tão depressa" (CANDIDO, 1992, p. 14), acabam incorporando o caráter transitório do veículo e não são produzidas com o intuito de permanecerem "na lembrança e na admiração da posteridade; e a sua perspectiva não é a dos que escrevem do alto da montanha, mas do simples rés-do-chão" (CANDIDO, 1992, p. 14). Existe uma oposição no pensamento de Candido entre tratar de assuntos cotidianos e ter vigência para além desse cotidiano. Mesmo que sua visão se refine na continuação do texto em relação ao contexto de surgimento da crônica: "retificando o que ficou dito atrás, ela não nasceu propriamente com o jornal, mas só quando este se tomou quotidiano, de tiragem relativamente grande e teor accessível, isto é, há uns cento e cinquenta anos mais ou menos [o que daria em torno de 1830]" (CANDIDO, 1992, p. 15); o mesmo não vai acontecer em relação à constituição do gênero que se forma nesse contexto complexo, tendo sua constituição sempre marcada por um olhar benévolo e pouco problematizador. Ainda se referindo à crônica como gênero, vai dizer ele:

No Brasil ela tem uma boa história, e até se poderia dizer que sob vários aspectos é um gênero brasileiro, pela naturalidade com que se aclimatou aqui e a originalidade com que aqui se desenvolveu. Antes de ser crônica propriamente dita foi "folhetim", ou seja, um artigo de rodapé sobre as questões do dia, - políticas, sociais. artísticas, literárias. Assim eram os da secção "Ao correr da pena"3, título significativo a cuja sombra José de Alencar escrevia semanalmente para o Correio Mercantil, de 1854 a 1855. Aos poucos o "folhetim" foi encurtando e ganhando certa gratuidade, certo ar de quem está escrevendo à toa, sem dar muita importância. Depois, entrou francamente pelo tom ligeiro e encolheu de tamanho, até chegar ao que é hoje.

Ao longo deste percurso, foi largando cada vez mais a intenção de informar e comentar (deixada a outros tipos de jornalismo), para ficar sobretudo com a de divertir. A linguagem se tomou mais leve, mais descompromissada e (fato decisivo) se afastou da lógica argumentativa ou da crítica política, para penetrar poesia adentro. Creio que a fórmula moderna, onde entra um fato miúdo e um toque humorístico, com seu quantum satis de poesia, representa o amadurecimento e o encontro mais puro da crônica consigo mesma (CANDIDO, 1992, p. 15).

\footnotetext{
${ }^{3}$ A série “Ao correr da pena” constituiu-se de folhetins de José de Alencar publicados no Correio Mercantil nos anos 1854-1855 e reunidos em livro em 1874.
} 

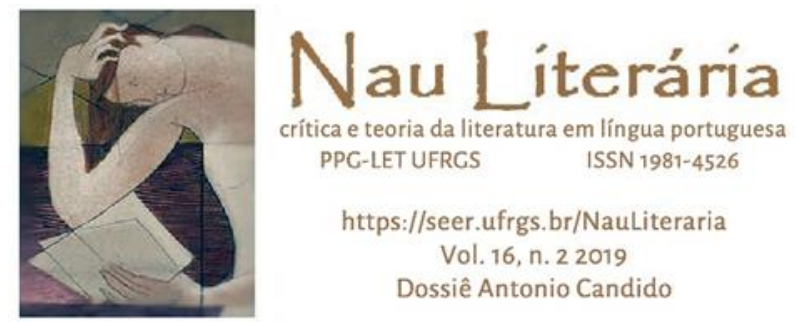

PPG-LET UFRCS ISSN 1981-4526

https://seer.ufrgs.br/NauLiteraria

Vol. 16, n. 22019

Dossiê Antonio Candido

Fato miúdo, humor e poesia, elementos da modernidade incorporados pela crônica marcam sua identidade como gênero. Nesse processo de constituição da crônica, no século XIX, mesmo com variações entre os autores, nela "ainda se notava mais o corte de artigo leve", que foi sendo acompanhado de uma crescente "dose poética" 4 . Para Candido (1992, p. 16), o fato é que a crônica, como gênero, é, pela contribuição de muitos autores, um "produto sui generis do jornalismo literário brasileiro" (CANDIDO, 1992, p. 16). De forma genérica, ele diz que as crônicas têm um "tom menor de coisa familiar" (CANDIDO, 1992, p. 17).

Na sequência, Candido (1992, p. 19) vai dizer diretamente que "simplicidade, brevidade e graça" são "próprias da crônica", são "traços constitutivos da crônica" e "são um veículo privilegiado para mostrar de modo persuasivo muita coisa que divertindo, atrai, inspira e faz amadurecer a nossa visão das coisas". Diz isso e refuta a "ideia falsa" de que a "leveza é superficial".

Se lembrarmos que em seu conhecido estudo, "O direito à literatura", ele concebe literatura da "maneira mais ampla possível", compreendendo desde o folclore e a lenda até as formas mais "complexas e difíceis da produção escrita das grandes civilizações" (CANDIDO, 2004, p. 174), percebemos que, embora oscile em alguns momentos, mesmo no limite com o jornalismo, a crônica ocupa para Candido um lugar dentro da literatura, possuindo as três faces que ele atribui a ela: construção de objetos autônomos como estrutura e significado; forma de expressão, ou seja, ressignifica a experiência humana no plano simbólico e, por fim, forma de conhecimento, mesmo que de modo difuso e inconsciente. Enfatizando o papel da forma nesse processo, o autor afirma que ao ordenar um mundo, a literatura, mesmo que não percebamos conscientemente, torna-se um fator que nos deixa mais capazes de ordenar nossa experiência e a visão que temos do mundo.

\footnotetext{
${ }^{4}$ Essa visão de Candido será retomada por Arrigucci Júnior (2001) e revela a proximidade de ambos que enxergam uma suposta evolução do gênero que teria como ponto de chegada Rubem Braga, cujas crônicas são carregadas de lirismo. Para ambos os críticos, mais ainda no caso de Arrigucci, Rubem Braga é um modelo de cronista, que serve de baliza para a avaliação dos demais. Nesse sentido, Antonio Candido (1992, p. 17) vai dizer o seguinte: "Acho que foi no decênio de 1930 que a crônica moderna se definiu e consolidou no Brasil, como gênero bem nosso, cultivado por um número crescente de escritores e jornalistas, com os seus rotineiros e os seus mestres." Entre estes, aquele estará "voltado de maneira praticamente exclusiva para este gênero: Rubem Braga". Já Arrigucci (2001, p. 55) afirmará: "Braga, embora poeta bissexto e contista eventual, escreve crônicas desde a década de 30 e foi decerto quem deu o maior grau de autonomia estética a esse gênero entre nós [brasileiros], tornando-se, por isso, um modelo de cronista".
} 

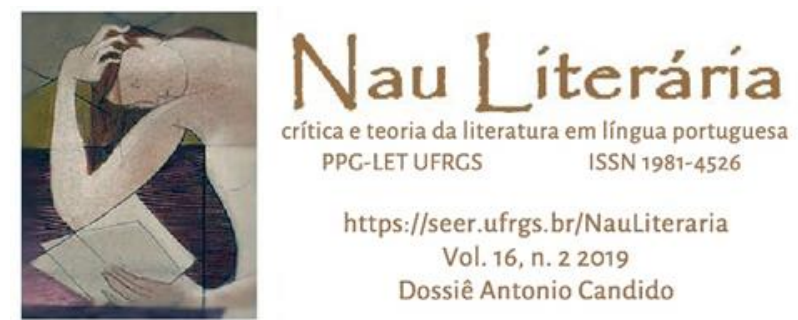

PPG-LET UFRCS ISSN 1981-4526

https://seer.ufrgs.br/NauLiteraria

Vol. 16, n. 22019

Dossiê Antonio Candido

Na relação com o conteúdo, de modo lapidar, ele destaca: “o conteúdo só atua por causa da forma, e a forma traz em si, virtualmente, uma capacidade de humanizar devido à coerência mental que pressupõe e que sugere" (CANDIDO, 2004, p. 178).

Para atingir os efeitos de transportar o leitor "ao mundo da imaginação" e fazê-lo voltar "mais maduros à vida" (CANDIDO, 1992, p. 20), o cronista se utiliza de vários meios. Então, o autor comenta a maleabilidade formal das crônicas, que podem assumir a forma de "diálogos", "marchar rumo ao conto, à narrativa mais espraiada com certa estrutura de ficção", parecer "anedotas desdobradas", aproximar-se "da exposição poética ou certo tipo de biografia lírica" (CANDIDO, 1992, p. 21).

A maior parte do pontuado por Candido (1992) sobre o gênero tornou-se uma espécie de lugar-comum sobre a crônica: leveza, assunto miúdo, humor, diversidade formal e vínculo com o dia a dia pelo jornal. Essa é a visão recorrente que reaparecerá, por exemplo, em Sá (1987) e Arrigucci Jr. (2001). Como lembra Chalhoub et alli (2005, p. 9-10), tais características haviam sido esboçadas em duas crônicas de Machado de Assis: uma em $1^{\circ}$ de agosto de 1876 e outra em $1^{\circ}$ de novembro do ano seguinte, ambas publicadas na Ilustração Brasileira ${ }^{5}$. Mesmo que:

apenas esboçadas na pena de Machado, acabaram, com os anos, por servir de base às tentativas de definição de uma essência para o gênero. Embora tenha por tempos garantido simpatia e condescendência à crônica, essa definição acabou por transformá-la em uma espécie de filha bastarda da arte literária (CHALHOUB et alli, 2005, p. 9).

De fato, esse modo de entender a crônica perpassa o texto de Candido (1992) que acrescentou a ela essa dimensão de gênero nacional. Destaca-se aqui que a análise que Candido faz da formação da crônica não é levado a cabo pelo método dialético que consolidou outros de seus estudos, como o "Dialética da Malandragem" (CANDIDO, 2010, p. 17-47), mesmo que até ele tenha merecido ressalvas no tocante a isso, como o faz Schwarz (2006, p. 153-154). A perspectiva adotada por Candido (1992) para estudar

\footnotetext{
${ }^{5}$ Hoje contamos com duas boas edições que reúnem as crônicas de Machado de Assis nessa série: ASSIS, Machado de. História de quinze dias / Machado de Assis; organização, introdução e notas: Leonardo Affonso de Miranda Pereira. - Campinas, SP: Editora da Unicamp, 2009. E ASSIS, Machado de. História de quinze dias, história de trinta dias: crônicas de Machado de Assis, Manassés; Sílvia Maria Azevedo (org.). - São Paulo: Editora Unesp, 2010. Como indica essa última referência, Machado escrevia a referida série com o pseudônimo de Manassés. A série mudou de nome quando a publicação da revista deixou de ser quinzenal e passou a ser mensal.
} 


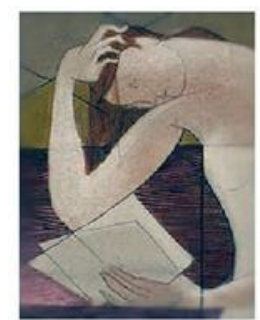

a crônica é antes culturalista, ou seja, toma um dado que é histórico e material e o transforma em característica, genericamente posta, da cultura brasileira. Veja-se que a materialidade da produção e da circulação da crônica (profissionais pagos, produto a ser vendido, presença de anúncios, periodicidade...) impõe limites a uma abordagem desse tipo e indica a necessidade de que o estudo disponha de maior rigor histórico e social.

Outro estudo sobre a crônica que, apesar dos méritos, sucumbiu a tal perspectiva, foi o de Arrigucci Jr. (2001, p. 51). Para ele: "Esse gênero de literatura ligado ao jornal está entre nós há mais de um século e se aclimatou com tal naturalidade, que parece nosso". Mesmo que "na origem" tenha dependido "da influência europeia", logo alcançou "porém, um desenvolvimento próprio extremamente significativo" (ARRIGUCCI JR., p. 53). Assim como Candido (1992), Arrigucci Jr. (2001) faz agudas observações sobre a complexidade do surgimento da crônica e seu contexto de produção e leitura, que exigiam um considerável desenvolvimento social. Nenhum dos dois críticos, contudo, busca averiguar os traços inscritos no gênero que tenham advindo desse contexto. Fica-se numa situação de consideração da crônica como um "gênero menor" e a tentativa de valorizála, apesar disso, como que pedindo desculpas ${ }^{6}$. Nesse processo, muitos elementos importantes acabam sendo levantados, mas o problema de uma análise mais materialista para o estudo de constituição do gênero continua em aberto.

\section{Crônica: trajetória e materialidade}

Antes de assumir o sentido modernamente atribuído a ela, "crônica" era sinônimo de "crônica histórica". Segundo Afrânio Coutinho (2008, p. 121), de todos os idiomas europeus modernos, o português é o único no qual a palavra "crônica" não designa mais apenas "crônica histórica". Até hoje nesses outros idiomas, "cronista" é aquele que narra os eventos históricos sem procurar estudá-los e interpretá-los (COUTINHO, 2008, p.

\footnotetext{
${ }^{6}$ Arrigucci Jr. (2001, p. 57-58) chega a dizer que ao escrever crônicas no jornal, os autores estavam "experimentando a mão" para e escrita do romance: "E de fato os escritores como que se preparavam, por esse meio, para um gênero maior e na aparência mais seguro por seu próprio inacabamento - o romance". Assim, ele retoma uma velha e unilateral fórmula que define a escrita da crônica como um "laboratório ficcional" (BRAYNER, 1982).
} 


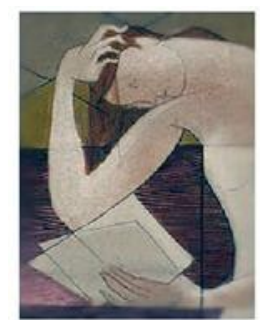

120). O sentido atual, designando "um gênero específico, estritamente ligado ao jornalismo", possivelmente foi sendo construído no século XIX, "não havendo certeza se em Portugal ou no Brasil" (COUTINHO, 2008, p. 121). Espacialmente no jornal, a crônica situava-se inicialmente ao pé da primeira página - daí, por exemplo, a designação de "vida ao rés-do-chão" que, como vimos, ganhou com Antonio Candido (1992). Esse espaço, antes dela, costumava ser ocupado pelo chamado "folhetim", lugar de publicação de muitos romances seriados e também de contos, mas que, antes de virar crônica, abrigava artigos variados do dia a dia, muito comum na França e que era "um espaço vazio destinado ao entretenimento" (MEYER, 1998, p. 113). Ou seja, era mais uma função e um espaço do que propriamente uma seção:

Aquele espaço vale-tudo suscita todas as formas e modalidades de diversão escrita: nele se contam piadas, se fala de crimes e de monstros, se propõem charadas, se oferecem receitas de cozinha ou de beleza; aberto às novidades, nele se criticam as últimas peças, os livros recémsaídos (...) (MEYER, 1998, p. 114).

Ao especificar-se, o folhetim acrescentava ao seu título a área que, naquele dia, seria comentada naquele espaço. No folhetim dramático, fazia-se a crítica teatral, no folhetim literário, as resenhas de livros, quando os assuntos eram diversos demais para serem acolhidos em uma categoria, eram os folhetins sobre variedades e coisas da vida. Por seu tremendo apelo comercial (a variedade de assuntos chamava atenção de um público bastante diversificado), os folhetins tiveram lugar de destaque no jornalismo francês e se expandiram par ao brasileiro (MEYER, 1998, p. 114).

A transição desse folhetim originário do jornalismo francês para a crônica jornalística costuma causar polêmica, e a tendência de demarcar a crônica como "brasileira" em oposição ao folhetim vem daí. O fato é que há uma zona de indeterminação entre os dois tipos de escrito, o que não quer dizer que não possam ser discerníveis. Em meados do século XIX no Brasil, contudo, esse discernimento não era possível. Os escritos de José de Alencar, “Ao correr da pena”, por exemplo, publicados de 1854 a 1855, tratados hoje sem discussão como crônicas, ainda eram chamados de folhetim, conforme título da seção que ocupou no Correio Mercantil e no Diário do Rio de Janeiro (cf. ALENCAR, [s.d.], p. 1 e 137). Do mesmo modo, Machado de Assis (2009, p. 55-58), em 1859, ao delimitar o perfil do "Folhetinista" - título do seu texto de 30 de 


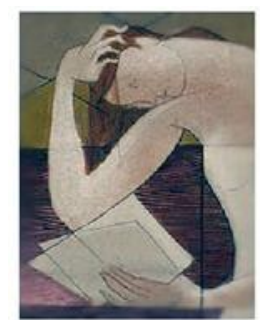

outubro no jornal $O$ Espelho - descreveu as mesmas características com as quais ele mesmo mais $\operatorname{tarde}^{7}$ (como apontamos anteriormente) definiria o cronista. O folhetinista, diz ele, como o "colibri" (ASSIS, 2009, p. 56), vai para um lado e para o outro em busca de assunto. Também com outros gêneros o folhetim se confundiu: "Folhetim era a crônica, mas também a novela ou romance, quando publicado em jornal" (COUTINHO, 2008, p. 124). Passado o período em que, em língua portuguesa, os termos crônica e folhetim designavam o mesmo produto jornalístico, "venceu e generalizou-se afinal o termo "crônica", ficando "folhetim" para designar mais a seção, na qual se publicavam não só crônicas senão também ficção e todas as formas literárias" (COUTINHO, 2008, p. 122). "Crônica", então, passou a "indicar relato e comentário dos fatos em pequena seção de jornais" para, por fim:

estender-se à definição da própria seção e do tipo de literatura que nela se produzia. Assim, "crônica" passou a significar outra coisa: um gênero literário de prosa, ao qual menos importa o assunto, em geral efêmero, do que as qualidades de estilo, a variedade, a finura e argúcia na apreciação, a graça na análise de fatos miúdos e sem importância, ou na crítica de pessoas. "Crônicas" são pequenas produções em prosa, com essas características, aparecidas em jornais e revistas (COUTINHO, 2008, p. 121).

Francisco Otaviano de Almeida Rosa (1825-1889), que escrevia no Jornal do Comércio desde 02 de dezembro de 1852, e também no Correio Mercantil, pouco depois, é visto por Afrânio Coutinho (2008, p. 124) como o iniciador da "crônica brasileira propriamente dita". Segundo o crítico, logo em seguida, em 1854, José de Alencar o substituiu no Correio Mercantil. Os escritos de Alencar, intitulados “Ao correr da pena", alternavam-se no mesmo jornal com as de Manuel Antônio de Almeida, cujas crônicas intitulavam-se "Páginas Menores". Nota-se com facilidade que a ideia de gênero menor está marcada desde o início da prática cronística no Brasil. Como vimos, essa designação acompanha as definições do gênero até hoje. Como questiona Coutinho (2008, p. 124), "Por que "menores" (...)? Por serem circunstanciais? Por estarem destinadas a produzir efeito transitório? Por serem escritas apressadamente?”. O crítico lembra que muitas vezes era o cronista que abria "caminho ao romancista", não no sentido de ser um

\footnotetext{
${ }^{7}$ Num texto de $1^{\circ}$ de agosto de 1876 e em outro de $1^{\circ}$ de novembro de 1877 , ambos publicados na Ilustração Brasileira, na seção Histórias de quinze dias.
} 


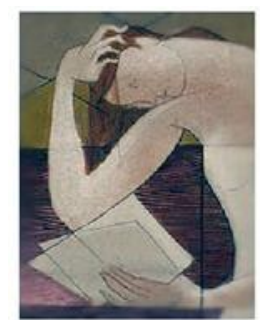

exercício de escrita, como assinalam Arrigucci Jr. (2001) e Sônia Brayner (1982), mas por iniciarem o diálogo com o público.

Como observa Chalhoub et alli (2005, p. 10), a perspectiva que considera a crônica dotada do "caráter despretensioso e datado de uma notícia de jornal" e "produzida por força das circunstâncias, sem obedecer a nenhum impulso criativo mais elevado" é a mesma que afirma "o caráter passageiro dessa literatura com data de validade, cujo brilho se esgotava com a edição seguinte da folha". Contudo, essa perspectiva só existe se não atentarmos "para o fato de que muitos romances e contos escritos na segunda metade do século XIX foram publicados originalmente em jornais, muitas vezes com pressão de prazos idêntica àquela que inibiria a qualidade das crônicas" (CHALHOUB et alli 2005, p. 10).

A título de ilustração, veja-se o que disse Ferreira de Araújo, um dos proprietários e redator-chefe de um dos mais importantes jornais do séc. XIX brasileiro, sobre a produção nas páginas do seu periódico, a Gazeta de Notícias: quando havia um debate em aberto em relação a alguma causa em que o jornal estava envolvido, ela era discutida imediatamente, seja em verso, em conto, em anedota ou qualquer seção do jornal, sem distinção de gênero para acolher a demanda (ARAÚJO, 1899, posição Kindle 11005). Não custa lembrar também que um livro como O Ateneu (crônicas de saudades), de 1888, foi "escrito dia a dia, no correr de três meses, para a Gazeta de Notícias" (COUTINHO, 2008, p. 127). Está posto, por tudo que foi dito, que aos poucos a crônica foi ganhando contornos próprios e se tornando independente do folhetim, mas que também guarda afinidades com ele, assim como com outros gêneros que se desenvolveram no transcurso de sua consolidação.

\section{Pressupostos e características da crônica}

Nas últimas décadas do séc. XIX, a crônica apresenta alguns de seus traços já cristalizados, pois eram recorrentes na produção daqueles que ocupavam a posição de cronista de jornal no Brasil desde a metade do século. Consideradas as experiências de autores como Francisco Otaviano, José de Alencar, Joaquim Manuel de Macedo, Manuel Antônio de Almeida, de Machado de Assis, entre outros (cf. COUTINHO, 2008, p. 124; 


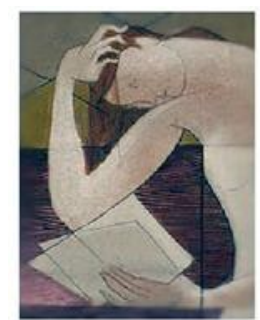

https://seer.ufrgs.br/NauLiteraria

Vol. 16, n. 22019

Dossiê Antonio Candido

CANO, 2004, p. 7-11), podemos inferir que os traços constitutivos do gênero já haviam se tornado convencionais nesse período. Quanto a isso, Franco Moretti (2007, p. 25 grifo do autor) destaca que o conceito de "convenção" é "essencial para a análise da cultura", isso "por que indica quando uma forma assumiu uma raiz social definitiva, penetrando na vida cotidiana, animando e organizando-a de maneira cada vez mais imperceptível e regular e, portanto, eficaz". A prática do gênero crônica no Brasil ao longo das décadas, ao mesmo tempo que reduziu a possível indeterminação em que cairia, regulamentou os seus modos de escrita.

A brevidade, o humor, a informalidade, a busca por assuntos variados que recebem tratamento aparentemente simples, a coloquialidade da linguagem, seu vínculo com o cotidiano e com o jornalismo estão postos nessas primeiras décadas de prática do gênero no Brasil. Ela é um "gênero de fronteira" (AGUIAR, 1997), por isso, em condição limítrofe absorve características diversas, da literatura, mas também de outras áreas. Talvez justamente por ocupar essa posição, ela

tem a capacidade de penetrar agudamente na matéria íntima de seu tempo e esquivar-se da corrosão dos anos, como se nela se pudesse sempre renovar, aos olhos de um leitor atual, um teor de verdade íntima, humana e histórica, impresso na massa passageira dos fatos esfarelando-se na direção do passado (ARRIGUCCI JR. (2001, p. 53).

De semelhança com sua ancestral, a crônica histórica, podemos dizer que a crônica moderna guarda a relação com o tempo. Entre os "vários significados da palavra crônica", Arrigucci Jr. (2001, p. 51) observa que todos "implicam a noção de tempo, presente no próprio termo que procede do grego chronos". Por fixar a continuidade do gesto humano na tela do tempo", pode-se dizer que sua "matéria principal" é "o que fica do vivido". Ela, então, luta contra o tempo, buscando eternizar o efêmero.

\section{Crônica e vida social brasileira}

Como temos visto, a crônica proporciona por suas características o tratamento mais íntimo dos temas que aborda. Seja pelo assunto geralmente ao alcance da maioria, pois colhido no cotidiano, seja pela linguagem coloquial, pela aparente leveza, mesmo que possa esconder um humor cortante, ela é facilmente vista como algo próximo. Além de tudo, está presente nos jornais e revistas, que tendem a circular de forma mais ampla 


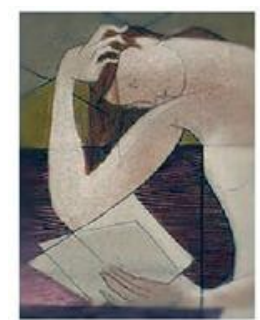

do que o livro. A crônica é, em suma, propensa à informalidade. Contudo, ao ser publicada em periódicos, penetra na esfera pública. Entre os vários limites nos quais esse gênero se encontra, o limite entre a formalidade e a informalidade é um deles, afinal, trata-se, em verdade, de encenação dessa informalidade, já que o narrador-cronista não é amigo do leitor nem vice-versa. Também ele não está conversando com o outro, mas escreveu um texto pelo qual foi pago e para cuja construção teve que cumprir alguns protocolos de escrita.

Esse limite entre a formalidade e a informalidade encena a imbricação entre o público e o privado. Edu Otsuka (mimeo, p. 4) oferece elementos para o estudo da crônica em perspectiva de sua "simbiose com elementos centrais da vida social e cultural do país" (OTSUKA, mimeo, p. 1). O mesmo autor questiona a caraterização do gênero como algo "brasileiro" e se pergunta de onde viria um certo "orgulho" ao se pensar assim. Otsuka (mimeo) entende que existe uma seletividade na escolha dos assuntos e do tom com que eram trazidos à tona nas crônicas e que essa seletividade está relacionada "com os efeitos particulares da organização econômico-social brasileira - historicamente fundada no sistema escravista" (OTSUKA, mimeo, p. 4). De modo que esse jeito ameno e familiar da crônica assinala um contexto em que se abdica da "sua potencial função pública, conformando-se antes aos padrões mais estreitos da esfera doméstica". Entre todos os gêneros, diz ainda Otsuka (mimeo, p. 4), a crônica é, "justamente, o lugar em que se elabora de modo mais acentuado o estilo que se molda pela atmosfera familiar". Assim, ela mantinha "características provenientes do modelo europeu", como "a leveza da expressão e o ziguezaguear na associação de ideias (...)”, mas essas se mostraram "também convenções adequadas para a estilização da informalidade e da arbitrariedade próprias às relações familistas".

Nessa seara, Otsuka (mimeo, p. 2) vale-se do estudo de Jürgen Habermas (2003) para debater a constituição da "esfera pública burguesa", conforme desenvolvida pelo teórico, mas estabelecendo seus limites na sociedade brasileira. Essa "esfera pública" corresponderia a uma espécie de intermediação entre os indivíduos privados organizados na sociedade civil e o poder público, sobre cujos assuntos esses mesmos indivíduos debatem ao mesmo tempo que questionam esse poder. Habermas (2003, p. 13-17) faz um histórico do que seria essa esfera pública ao longo do tempo, partindo da Grécia antiga e 


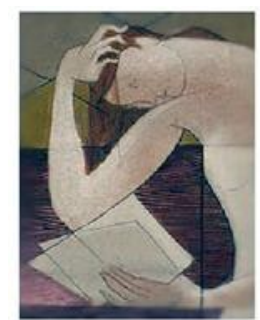

chegando à sociedade burguesa, dita moderna. Também traz elementos etimológicos da palavra "público" e destaca seu vínculo, não tão óbvio para nós hoje, com a publicidade. Da mesma forma, nem tudo que é considerado "público" está ao alcance de qualquer um. Focando no que nos interessa mais, Habermas (2003) faz o recorte histórico classicamente materialista ${ }^{8}$, delimitando as transformações do seu objeto de estudo e o que seria sua versão "burguesa" com a desintegração da sociedade feudal, a partir da qual delineou-se a esfera da sociedade burguesa que, dizendo-se representante da autonomia privada, contrapõe-se ao Estado. Sem podermos nos dedicar aqui às contradições próprias dessa esfera pública burguesa, "que nunca existiu de fato com a universalidade que seus membros pretendiam" (OTSUKA, mimeo, p. 2), ou diziam pretender, destacamos que a tradição familista comentada por Otsuka (mimeo) para entender as características da crônica estava alicerçada no clientelismo e na economia rural explorada pela elite brasileira. Essa tradição se afasta da forma como o processo se desenvolveu em países europeus que ocupavam o centro do capitalismo ocidental no século XIX.

A ideia de esfera pública burguesa, falsamente universalizante, "tinha apoio na expansão da imprensa periódica, sobretudo o jornal, que incitava o público a participar e podia então ser plausivelmente concebido como o principal veículo para a formação da opinião pública" (OTSUKA, mimeo, p. 2). No cotidiano e no jornal esses valores compartilhados eram, respectivamente, vividos e representados. A crônica, por sua vez, traz em si as marcas de seu contexto, incorporando a matéria cotidiana como tema, mas ao mesmo tempo apresenta esse nexo com o jornal e com a notícia, fundindo as vozes locais ao processo específico de internacionalização pelo qual o país passava. Se o modo como o processo se desenvolveu na Europa já era marcadamente seletivo, aqui essa desigualdade se acentuou em função da maior desigualdade social e do contexto contraditório em que o vocabulário científico e a pretensão de cópia de modelos estrangeiros convivia com práticas que lembram mais sociedades ditas primitivas, com permanência de alguns valores comunitários, mas também baseados na "rixa" (para falarmos com Edu Otsuka, 2007), que incluía a violência física. Em um universo em que a defesa da honra era feita com a retaliação pessoal, em função da falta de regulamentação

\footnotetext{
${ }^{8}$ Veja-se Marx e Engels (2012) e Engels (2008).
} 


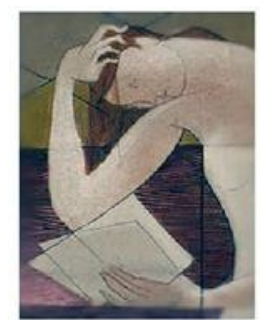

da vida social, os valores compartilhados pela cultura letrada diziam mais respeito ao repertório europeu, desligado da experiência brasileira, mas ao mesmo tempo utilizado para suas disputas internas. Assim, o desenvolvimento da crônica vai despontar no contexto do século XIX, momento de grande evidência das contradições próprias da situação periférica brasileira, em que a perspectiva pretensamente modernizante entrava em contraste com a matéria local. Elas, portanto, "afloram em meio ao material do passado, herança persistente da sociedade tradicional, as novidades burguesas trazidas pelo processo de modernização do país, de que o jornal era um dos instrumentos" (ARRIGUCCI JR., 2001, p. 57).

Se enfatizarmos o contexto mais imediato do período final do império, o tratamento íntimo e familiar dado aos temas e sua relação com a precariedade da esfera pública por aqui ganha nova dimensão. Segundo Starling (2008, p. 31), “durante a década de 1880, na cidade do Rio de Janeiro, a rua transformou-se no locus capaz de fazer convergir acontecimentos e temas da vida política do país e o homem comum”, tratavase do "fenômeno de reconfiguração política do espaço urbano". Nesse sentido, nota-se um esforço para construção dessa esfera pública, restrita à elite letrada. Contudo, esse suposto momento em que a política parecia mais próxima de cada um é ilusório. Como demonstra Heloísa Starling (2008, p. 33), naquele momento projetava-se um sistema político cujo "centro de equilíbrio sustentava-se num sistema constitucional rigidamente oligárquico, que estava longe de conter uma preocupação com a ampliação da participação política dos grupos sociais existentes na condução dos negócios públicos”. Juntemos a isso a reforma eleitoral da lei Saraiva, de 1881, com a qual o número de eleitores caiu drasticamente: $0,8 \%$ da população total tinha efetivamente votado (HOLANDA, 2008, p. 284-5). Sendo que cerca dez anos antes, em 1872, esse percentual era de 13\% da população total (CARVALHO, 2001, p. 39). Para Edu Otsuka (2007, p. 1$2 ; 5)$, "a crônica foi se tornando o que veio a ser à medida que se desprendia do comentário sobre os fatos políticos, sociais, teatrais, literários etc. e se libertava do andamento argumentativo" e neste "registro não argumentativo, o leitor não é incitado ao debate racional, não é convocado como sujeito esclarecido e independente, mas é antes engolido pela subjetividade do cronista ou, pelo menos, levado a mergulhar nela voluntariamente". 

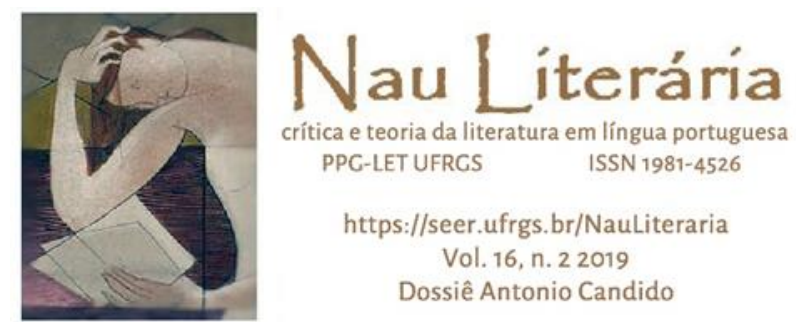

PPG-LET UFRGS ISSN 1981-4526

https://seer.ufrgs.br/NauLiteraria

Vol. 16, n. 22019

Dossiê Antonio Candido

Conforme Otsuka (mimeo, p. 4) e Boenavides (2012, p. 111 e 2013, p. 64), essa dimensão da crônica pode ser aproximada do que Sérgio Buarque de Holanda (2002, p. 1044-1055) definiu como comportamento cordial presente na sociedade brasileira. Ele seria uma espécie de herança maldita proveniente da síntese da colonização e do domínio do patriarcado rural. Tal comportamento adviria da falta de limites entre o público e o privado e estaria relacionado ao modo como o Estado se constituiu por aqui em contraste com sua suposta formação clássica nos principais países do capitalismo ocidental:

O Estado não é uma ampliação do círculo familiar e, ainda menos, uma integração de certos agrupamentos, de certas vontades particularistas, de que a família é o melhor exemplo. Não existe entre o círculo familiar e o Estado, uma gradação, mas antes uma descontinuidade e até uma oposição. [Estado e família] pertencem a ordens diferentes em essência. Só pela transgressão da ordem doméstica e familiar é que nasce o Estado e que o simples indivíduo se faz cidadão, contribuinte, eleitor, elegível, recrutável e responsável, ante as leis da Cidade. Há nesse fato um triunfo do geral sobre o particular, do intelectual sobre o material, do abstrato sobre o corpóreo (...). A ordem familiar, em sua forma pura, é abolida por uma transcendência (HOLANDA, 2002, p. 1044).

Pelo modo como se desenvolveram as relações entre o rural e o urbano, entre o público e o familiar no Brasil, esse suposto modelo de superação do interesse individual pelo coletivo não vigorou.

No Brasil, onde imperou, desde tempos remotos, o tipo primitivo da família patriarcal, o desenvolvimento da urbanização - que não resulta unicamente do crescimento das cidades, mas também do crescimento dos meios de comunicação, atraindo vastas áreas rurais para a esfera das cidades - ia acarretar um desequilíbrio social, cujos efeitos permanecem vivos ainda hoje.

Não era fácil aos detentores das posições públicas de responsabilidade, formados por tal ambiente, compreenderem a distinção fundamental entre os domínios do privado e do público. Assim, eles se caracterizam justamente pelo que separa o funcionário "patrimonial" do puro burocrata conforme a definição de Max Weber. Para funcionário "patrimonial", a própria gestão política apresenta-se como assunto de seu interesse particular; as funções, os empregos e os benefícios que deles aufere, relacionam-se a direitos pessoais do funcionário e não a interesses objetivos, como sucede no verdadeiro estado burocrático, em que prevalecem a especialidade das funções e o esforço para se especialização das funções e o esforço para se assegurarem garantias jurídicas aos cidadãos. A escolha dos homens que irão exercer funções públicas faz-se de acordo com a confiança pessoal que mereçam os candidatos, e muito menos de acordo com suas capacidades próprias. Falta a tudo a ordenação impessoal que caracteriza a vida do Estado burocrático (HOLANDA, 2002, p. 1048-1049). 

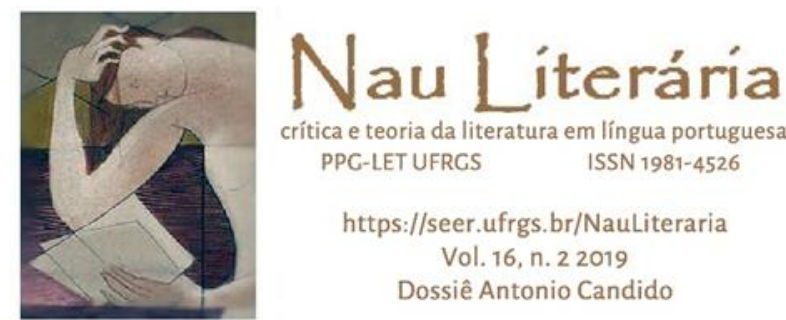

Essa é a dimensão pública da "cordialidade" brasileira, que, de acordo com o historiador, deve ser tomada em seu sentido etimológico, aquilo que é tão íntimo que provém do coração e, por isso, leva a uma "aversão ao ritualismo social", de onde pode emergir tanto a amizade quanto a inimizade. Linguisticamente, tal característica manifesta-se em um "pendor acentuado para o emprego dos diminutivos" que "serve para nos familiarizar mais com as pessoas ou os objetos e, ao mesmo tempo, para lhes dar relevo" (HOLANDA, 2002, p. 1051). No discurso do cronista, ao dar tratamento íntimo aos temas públicos, como quem conversa com seu leitor, está inscrito essa expansão da vida familiar sobre a pública. A informalidade no tratamento dos assuntos, a aparente despretensão e a linguagem coloquial aparecem como formalização da cordialidade.

Cabe evitar que tal caracterização seja abordada por um viés culturalista, o que traria prejuízos tanto para o entendimento da crônica quanto para o da sociedade na qual ela está inserida. Para tentar não cometer esse equívoco, retomo aqui o que Francisco de Oliveira (2012) escreveu sobre o "jeitinho brasileiro". Este seria um "peculiar modo nacional de livrar-se de problemas, ou de falsificá-los" (OLIVEIRA, 2012, p. 3) e teria no "homem cordial" de Sérgio Buarque de Holanda sua "própria encarnação" (OLIVEIRA, 2012, p. 4). O autor, para fazer suas considerações, refere-se ao estudo de Antonio Candido (2010) sobre as Memórias de um sargento de milícias (1854). Para Oliveira (2012, p. 4), o olhar benevolente de Candido sobre a malandragem por ele estudada-e, dizemos nós, de certo modo criticada, embora também enaltecida, tanto por Schwarz (2006) quanto por Otsuka (2007) - se deve ao fato de o crítico respeitar "tanto o brasileiro pobre que aborda as figuras populares com uma reverência quase mística", isso porque "nossa sociedade é tão obscenamente desigual que qualquer crítica às classes dominadas não passa de preconceito - mais um - dos ricos".

Contudo, Francisco de Oliveira é direto e nesse seu corte nos apoiaremos. Diz ele: "busco desenvolver uma investida mais nitidamente materialista" (OLIVEIRA, 2012, p. 4). E depois expõe sem rodeios a sua tese: “o jeitinho é um atributo das classes dominantes brasileiras que se transmitiu às classes dominadas" (OLIVEIRA, 2012, p. 4). Ele indica um caminho precioso para debater o problema: a concepção de ideologia provinda do marxismo, especificamente de A ideologia alemã, de Marx e Engels, para sustentar a tese de que o jeitinho (e, portanto, a cordialidade) correspondem a "atributos das classes 


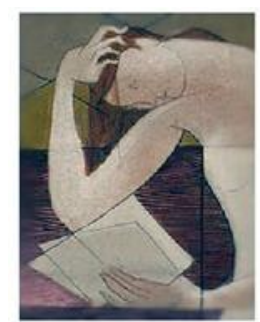

https://seer.ufrgs.br/NauLiteraria

Vol. 16, n. 22019

Dossiê Antonio Candido

dominantes brasileiras" transmitidos "às classes dominadas" (OLIVEIRA, 2012, p. 4).

Vejamos a concepção de Marx e Engels sobre o assunto:

As ideias da classe dominante são, em cada época, as ideias dominantes, isto é, a classe que é a força material dominante da sociedade é, ao mesmo tempo, sua força espiritual dominante. A classe que tem à sua disposição os meios da produção material dispõe também dos meios da produção espiritual, de modo que a ela estão submetidos aproximadamente ao mesmo tempo os pensamentos daqueles aos quais faltam os meios da produção espiritual. As ideias dominantes não são nada mais do que a expressão ideal das relações materiais dominantes, são as relações materiais apreendidas como ideias (MARX e ENGELS, 2007, p. 47, grifos dos autores).

A análise de Francisco de Oliveira (2012) mostra como um "jeitão" da elite, de classe, foi universalizado como caráter nacional brasileiro. Trata-se de um atributo transmitido pela elite. $\mathrm{O}$ modo de apropriação pode trazer os índices de resistência, de desvio ou de transgressão desse atributo, mesmo que aparentemente o afirme. Em síntese, o fato de o Brasil ter uma elite cordial não quer dizer que "o brasileiro" o seja. Contudo, como a elite dispõe de meios de difusão e reprodução de sua ideologia, tal característica, definida em base material e com corte de classe, expande-se e falsamente se transforma em traço cultural, englobando todas as classes, aparentemente sem distingui-las. $\mathrm{Na}$ prática, contudo, as manifestações da cordialidade variam conforme o pertencimento de classe. É o "jeitão" da elite e o "jeitinho" dos pobres". Os materialmente dominados - isto é, os não detentores dos meios de produção - passam, então, a ser também ideologicamente dominados e sua consciência se volta contra eles mesmos. De acordo com Leandro Konder:

Marx concluiu que a possibilidade de que a consciência se iludisse a respeito da sua própria natureza tinha surgido no processo em que os seres conscientes promoveram a dilaceração do tecido social. Mais precisamente, tinha surgido a divisão social do trabalho, com o aparecimento das classes sociais em colisão (2002, p. 40 - 41).

\footnotetext{
${ }^{9}$ Para uma mediação bem construída de um conceito cuja aplicação deve variar conforme a classe em questão, mas que também passou e passa por um processo de generalização que pretende desconsiderar justamente as especificidades de classe, veja-se Araújo e Reis (2015), em que a prática do "favor" é analisada em Os Ratos (1935), de Dyonélio Machado. O artigo mostra que o favor na relação entre Naziazeno e o diretor é de um tipo diferente do favor entre aquele e Duque.
} 


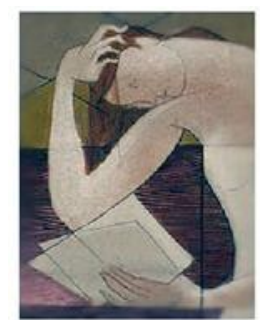

Ou seja, a falsa produção da consciência é trabalho da burguesia. A consciência se desliga da própria existência concreta, que passa a ser enxergada com os olhos da classe dominante. "No Brasil", diz Oliveira (2012, p. 4), a classe dominante burlou de maneira permanente e recorrente as leis vigentes" e o "drible constante nas soluções formais propicia a arrancada rumo à informalidade generalizada. E se transforma, ao longo da perpétua formação e deformação nacionais, em predicado dos dominados".

De modo nenhum tenho a pretensão de invalidar a obra, sequer o conceito de cordialidade elaborado por Sérgio Buarque de Holanda. Essa generalização, que hegemoniza um dado de classe e o torna nacional, precisa, contudo, ser eliminada. Não vejo forma mais lapidar de entender a cordialidade em base materialista do que essa indicada por Francisco de Oliveira (2012).

Para o maior aproveitamento desse debate para o estudo da crônica, é necessário ainda tocar em dois pontos: a questão do Estado e da família. Isso porque os principais elementos levantados aqui para definir esse perfil cordial que teria migrado como traço esteticamente formalizado para a crônica dizem respeito diretamente a isso. A primeira questão refere-se à maneira como o Estado aparece no estudo de Sérgio Buarque de Holanda. Grosso modo, fica dito que o Estado é uma instituição objetiva, oposta em tudo aos interesses privados. Lênin (2010, p. 27), contudo, ao estudar a concepção marxista de Estado, é taxativo: "O Estado aparece onde e na medida em que os antagonismos de classe não podem objetivamente ser conciliados. E, reciprocamente, a existência do Estado prova que as contradições de classes são inconciliáveis". O Estado é o produto e a manifestação do antagonismo inconciliável das classes. Mais adiante ele complementa: “O Estado é a organização especial de uma força, da força destinada a subjugar determinada classe" (LÊNIN, 2010, p. 45). A concepção de Estado que transparece em “O homem cordial” está mais próxima das concepções que Lênin (2010, p. 27) atribui aos "ideólogos burguesas", que estabelecem que "Estado é o órgão de conciliação das classes". A descrição do Estado burguês clássico como objetivo e imparcial é fruto da própria dominação da classe cujos interesses esse Estado defende.

Por fim, a questão da família que aparece nas referências à cordialidade e sua tradição familista de tratar como próprios o que é público. Assim como Lênin fez em relação ao Estado, podemos fazer em relação a essa família e perguntar: família de quem? 


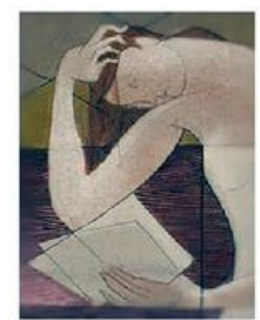

https://seer.ufrgs.br/NauLiteraria

Vol. 16, n. 22019

Dossiê Antonio Candido

Ou melhor, família de que classe pode, na formação histórica deste país, apropriar-se e fazer uso privado do que é público? Conforme Marx e Engels (2007, p. 33-34), cada família "no início constitui a única relação social", mas "torna-se mais tarde (...) uma relação secundária", que é a relação com as instituições sociais. O desenvolvimento desse caminho deve-se dar "segundo os dados empíricos existentes e não segundo o "'conceito de família"”. Conforme Chalhoub (2001, p. 174, grifo do autor):

Concretamente, isto significa reconhecer a impossibilidade de discorrer sobre $a$ família brasileira, enquanto modelo ideal pairando sobre nossas cabeças e determinando as ações dos agentes históricos independentemente das situações de classe vivenciadas por esses agentes na prática cotidiana da vida.

Da mesma forma que há um conceito de Estado não pensado em termos de classe no capítulo "O homem cordial", há também um conceito de família, que é a família burguesa, que faz uso privado do Estado. A própria designação de "Homem cordial", embora não aprofundemos aqui a discussão de gênero, indica uma visão patriarcal e de elite sobre o assunto. Com igual efeito ao tratamento dado ao Estado, a concepção de família acaba reproduzindo e estendendo a todos o caráter da elite brasileira, em cuja sociedade não houve passagem da família patriarcal para a burguesa, mas a conservação de valores patriarcais na aparente afirmação da família nuclear. Trata-se de um modelo burguês, que existe mais como ideologia do que na realidade. Tendo como efeito real causado pela ideologia a propagação de seu suposto modelo como modelo geral para a sociedade.

\section{$4 \mathrm{O}$ cronista, o leitor e a crônica como forma-mercadoria}

O folhetim oriundo da França, pelos processos que descrevemos no início deste texto, foi um produto jornalístico muito bem recebido no jornalismo brasileiro e que, depois de diversas etapas de sua migração, misturou-se e separou-se do que se consolidou como gênero crônica no Brasil do séc. XIX. Se tomarmos a leitura e ao ensino em geral no país nesse período, veremos que o analfabetismo e a ausência de educação universal laica em tudo contrasta com a França, no qual o quadro oposto (alfabetização ampla e laicização do ensino) implicou o aumento do público leitor e no fortalecimento dos folhetins. No Brasil, conforme Hélio de Seixas Guimarães: 
Ao longo de todo o século XIX, os alfabetizados não ultrapassaram os $30 \%$ da população brasileira, e não se verificaram alterações de perfil e dimensão do leitorado (...). Em 1872, apenas $18,6 \%$ da população livre e $15,7 \%$ da população total, incluindo escravos, sabiam ler e escrever, segundo dados do recenseamento; entre a população em idade escolar (6 a 15 anos), que somava 1.902 .454 meninos e meninas, apenas 320.749 frequentavam escolas, ou seja, 16,9\%. Já em 1890, a porcentagem diminuiu: apenas 14,8\% sabiam ler e escrever. Ainda segundo o censo de 1872, que apurou uma população de quase 10 milhões de habitantes, apenas 12 mil frequentavam a educação secundária e havia 8 mil bacharéis no país ${ }^{10}$ (2004, p. 65-66).

A restrição de público talvez enfatizasse o privilégio da posição do cronista, aproximando-o, por esse aspecto, da elite local, cuja "homogeneidade ideológica" e distinção advinha muito do fato de formarem uma "ilha de letrados num mar de analfabetos" (CARVALHO, 2010, p. 21; 65). Contudo, para não cairmos no reducionismo e não objetificarmos os escravizados, à maneira dos escravocratas, lembremos, nessa questão do universo letrado do período, um caso trazido por Marialva Barbosa (2010). Ela conta a história, transcorrida em 1886, de uma criança escravizada, de nome Eduarda, que, após ser espancada por sua proprietária, saiu pelas ruas com hematomas e várias marcas visíveis da tortura sofrida. A menina tencionava ir à Chefia de polícia, mas foi convencida por uma senhora na rua de, em vez disso, ir e à redação do jornal Gazeta da tarde, que pertencia ao abolicionista José do Patrocínio. Da redação desse jornal, ela foi encaminhada a uma vara de justiça, de onde, junto com outra escravizada do mesmo cativeiro, foi levada ao médico para ser tratada. Simultaneamente, Patrocínio divulgou o caso para diversos outros órgãos de imprensa. A partir disso, "Forma-se um cortejo com líderes abolicionistas e alguns jornalistas condunzindo as tortuadas e que se dirige às redações dos principais jornais da cidade: Vanguarda, Diário de Notícias, O Paiz, O Apóstolo, Gazeta de Notícias e Jornal do Comércio" (BARBOSA, 2010, p. 86-87). Mesmo os periódicos que não eram antiescravagistas, no dia seguinte estamparam a notícia em suas páginas, criticando a violência cometida. Note-se que Eduarda, embora alijada da possibilidade de leitura, fez uso do prestígio e da repercussão potencial dos órgãos de imprensa. Analfabeta, manejou a cultura letrada a seu favor.

${ }^{10} \mathrm{O}$ autor contrasta esses dados com o de países como Inglaterra, França e Estados Unidos, nos quais, em meados da década de 1870, o percentual de alfabetização variava de 70 a 90\% (GUIMARÃES, 2004, p. $64)$. 


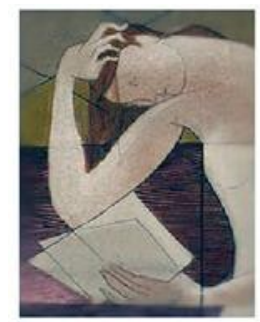

https://seer.ufrgs.br/NauLiteraria

Vol. 16, n. 22019

Dossiê Antonio Candido

Era nesse contexto contraditório e fascinante que se produzia crônica no Brasil da época. A função de cronista, então, esteve no centro do processo. Ela surge, junto com a crônica, claro, num período de "sucessão cada vez mais acelerada dos fatos" e de um mundo cada vez mais complexo que traz imposições mais exigentes ao entendimento humano" e dele "espera-se (...) uma espécie de "intervenção" no cotidiano, orientando o leitor na compreensão desse mundo (CHALHOUB, et alli, 2005, p.11-15). A mesma imersão do cronista no seu tempo é assinalada por (ARRIGUCCI JR., 2001, p. 57):

\begin{abstract}
O próprio cronista estava assim metido num processo histórico cuja dimensão geral era extremamente complexa e difícil de apreender, tendendo a escapar-lhe, mas cujos resultados muitas vezes discordantes se impunham à sua observação, pedindo tratamento artístico novo. Chamado a se situar diante de fatos tão discrepantes, dá de início a impressão de tateio sobre a matéria moderna no jornal, feita de novidades fugitivas, como se estivesse experimentando a mão (ARRIGUCCI JR., 2001, p. 57).
\end{abstract}

Importantes esses comentários sobre a posição histórica do cronista, pois não nos deixam esquecer que a falta de especialização de mão de obra intelectual no início de nossa formação cultural obrigava que uma mesma pessoa atuasse na imprensa, na política, na literatura, no funcionalismo público e, às vezes, no ensino. Trata-se de uma posição flexível por si, que ia na contramão da especialização intelectual. O cronista é comentador e transformador do cotidiano, "matéria-prima do vivido" (ARRIGUCCI JR., 2001, p. 52) a partir da crônica, um "fato moderno", o que significa estar submetida "aos choques da novidade, ao consumo imediato, às inquietações de um desejo sempre insatisfeito, à rápida transformação e à fugacidade da vida moderna” (ARRIGUCCI JR., 2001, p. 53). Como nota Edu Otsuka (mimeo, p. 5):

Acresce que não é irrelevante, para a caracterização da crônica moderna, o fato de o cronista frequentemente narrar experiências pessoais ou que pelo menos criam a ilusão de trazer o leitor para dentro do âmbito de sua intimidade, partilhando com ele suas impressões e opiniões pessoais. Despida da intenção de persuadir racionalmente por meio do encadeamento lógico de argumentos, a crônica convence antes pela afabilidade do cronista, pelo inusitado dos juízos e pelo modo espirituoso com que os expressa. 


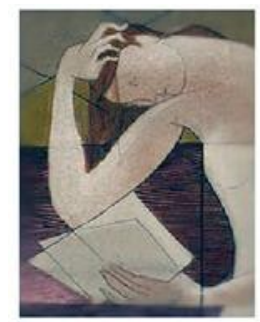

A falta da existência de uma tradição teórica para o estudo da crônica faz falta, mas aqui vamos arriscar uma adaptação ${ }^{11}$. Moretti (2000, p. 178-179), ao estudar a expansão do romance, propõe a construção do objeto por um triângulo: "forma estrangeira, material local e forma social. Simplificando um pouco: enredo estrangeiro, personagens locais e ainda voz local", então ele assinala que "é precisamente nessa terceira dimensão que esses romances parecem ser mais instáveis - mais incômodos", para o crítico. Isso é coerente, já que "o narrador é o polo de comentário, de explicação, de avaliação quando os "modelos formais" estrangeiros (ou a efetiva presença estrangeira, nesse particular) fazem os personagens agir de maneira estranha”. Portanto, sua hipótese é a de que a voz narrativa local é uma intermediária entre a forma europeia (no caso dele o romance, no do presente estudo seria o folhetim) e a matéria local. Buscamos adaptar aqui esse procedimento para o estudo da posição do narrador-cronista.

Segundo Schwarz:

O trabalho do escritor não é, em primeiro lugar, a transformação de formas literárias prévias (embora esta dimensão exista). Pelo contrário, trata-se da formalização do não-literário, o que naturalmente leva a transformações da série literária também, criando a aparência de uma evolução autônoma (2006, p. 148).

Se assim for, no triângulo de Moretti a matéria exerce mais pressão do que o indicado por ele, e na crônica isso se torna mais evidente, já que sua matéria-prima básica é o cotidiano. Talvez, outra necessária adaptação sobre o exposto por Moretti (2000) no tocante ao estudo do romance seja o maior peso do suporte. Muito forte também no caso dos romances-folhetins, para a crônica o periódico era no século XIX suporte inicial obrigatório. O jornal na imprensa comercial, como o livro em geral, é uma mercadoria. Seus trabalhadores estão sujeitos a um ritmo de produção já dito moderno, com prazos que precisam ser cumpridos para que as vendas aconteçam e o dinheiro entre. Assim, sua escrita segue o ritmo de produção, levando os cronistas a pularem de assunto em assunto e a inventá-los quando não o tinham, não para atender qualquer impulso criativo, mas para obedecer ao prazo de entrega estabelecido por relação de trabalho. Talvez isso permita que leiamos em nova chave a dimensão da matéria da crônica. Do mesmo modo,

\footnotetext{
${ }^{11}$ A ideia de tal adaptação consta no projeto de pesquisa sobre as Balas de estalo do qual fiz parte e foi construída por Antônio Sanseverino (2008, p. 16).
} 


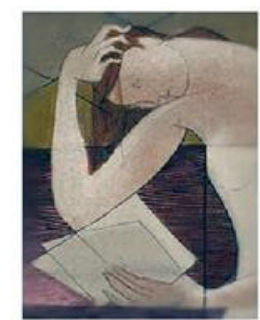

essa condição de produção e a busca por assuntos variados impunha a busca por formas variadas de trazer esse assunto a público. Ao ritmo das publicações e à diversidade de formas junta-se o estilo de escrita da crônica, com seu tom de conversa, como mecanismos que buscavam atender a um público, o mais amplo possível para facultar mais vendas. Desse modo, experimentação formal e características estéticas se confundem com estratégias comerciais.

O caráter brasileiro da crônica pode reaparecer aqui em nova perspectiva. Talvez ela seja índice da forma como a elite brasileira (por intermédio da imprensa) se apropriou dos modos de produção moderno. No caso, o jornal (produção em série, comercial, segundo meios modernos etc.) é uma forma internacional atravessada não apenas pela matéria local, como pelo modo de ser local. Assim, o artigo de opinião e o debate da esfera pública burguesa ganham feição ou da crônica ou da polêmica. Em outros termos, o debate público vira rixa (polêmica) ou vira bate-papo-de-bar (crônica). Moderno e periférico, o debate se realiza, sem realizar, bloqueado. Do mesmo modo, a crônica não se autonomiza como forma literária, já que marcada como mercadoria, associada à venda de jornais, sendo mais um produto deles. Para Marx (2013, p. 113-158), as mercadorias são na verdade formas, cortinas de fumaça que escondem as relações de produção e a luta de classes que constituem seu verdadeiro conteúdo. Temos visto, avançando no argumento, que é importante não tratar a crônica como um "ser estranho" enquanto produção cultural na sua relação com outros gêneros. Ela guarda fortes semelhanças com a criação de outros tipos de obras em circulação no séc. XIX. No seu caráter de formamercadoria, do mesmo modo, a crônica revela mais diretamente uma contradição de toda construção cultural da sociedade burguesa, que é a centralidade das condições materiais de produção e revela também a falsidade da suposta autonomia absoluta da obra de arte. Contudo, não podemos entendê-la sem seu traço local, como se fosse uma mercadoria genérica. Sérgio Buarque de Holanda (2002, p. 1052), no "Homem cordial”, refere-se ao negociante da Filadélfia que se espantou "ao verificar que, no Brasil como na Argentina, para conquistar um freguês tinha necessidade de fazer dele um amigo" (HOLANDA, 2002, p. 1052). Lembremos o tom íntimo, de coisa menor e próxima e do nosso dia a dia, de conversa despretensiosa e caseira da crônica. Afinal, por aqui, até para vender tem que ser "amigo". 


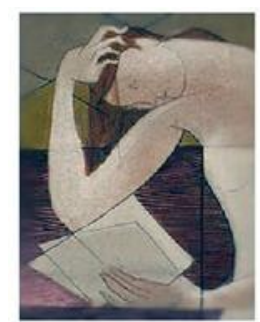

\section{Referências}

AGUIAR, F. (org.). Gêneros de fronteira: cruzamento entre o histórico e o literário. São Paulo: Xamã, 1997.

ALENCAR, José de. Ao correr da pena. [s.d.] Domínio público. Disponível em: http://www.dominiopublico.gov.br/pesquisa/PesquisaObraForm.do. Acessado em 07 de ago. 2019.

ARAÚJO, Ferreira de. Press. In.: SANTA-ANNA NERY, Frederico José de. (org.) Le Brésil en 1889: avec une carte de l'empire en chromolithographie, des tableaux statistiques, des graphiques et des cartes. Paris: Charles Delagrave, 1889.

ARAÚJO, H. J. V.; REIS, O. A. L. Favor, dívida impagável e forma literária em 'Os ratos'. Revista Cerrados (Brasília. Online), v. 1, p. 39-53, 2015.

ARRIGUCCI JUNIOR, Davi. Enigma e comentário: ensaios sobre literatura e experiência. São Paulo: Companhia das Letras, 2001.

ASSIS, Machado de. História de quinze dias, história de trinta dias: crônicas de Machado de Assis, Manassés; Sílvia Maria Azevedo (org.). - São Paulo: Editora Unesp, 2010.

História de quinze dias / Machado de Assis; organização, introdução e notas: Leonardo Affonso de Miranda Pereira. - Campinas, SP: Editora da Unicamp, 2009.

BARBOSA, Marialva. Histórica cultural da imprensa: Brasil, 1800-1900. Rio de Janeiro: Mauad X, 2010.

BOENAVIDES, William Moreno. A cordialidade de Lélio: Machado de Assis nas Balas de estalo. Organon, n. 28, v. 55, Porto Alegre, p. 55-71, jul./dez. 2013.

As formas da intervenção: política nas Balas de Estalo de Machado de Assis. 176 f. Dissertação (Mestrado em Literatura Brasileira) - Instituto de Letras, Universidade Federal do Rio Grande do Sul, Porto Alegre, 2012.

BRAYNER, Sonia. Metamorfoses machadianas: laboratório ficcional. In: BOSI, Alfredo et alli. Machado de Assis. São Paulo: Ática, 1982. (Grandes escritores, 1)

CANDIDO, Antonio. Dialética da malandragem. In.: $O$ discurso e a cidade. $4^{\mathrm{a}}$ ed. Rio de Janeiro: Ouro sobre azul, 2010.

Vários escritos. $4^{\mathrm{a}}$ ed. reorganizada pelo autor. São Paulo | Rio de Janeiro: Ouro sobre Azul, 2004. 


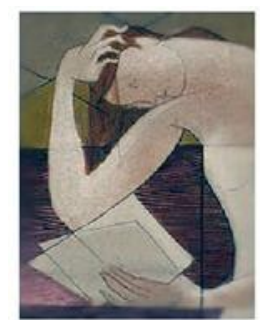

1993.

"A vida ao rés do chão". In.: Recortes. São Paulo: Companhia das Letras,

"A vida ao rés do chão". In.: Setor de filologia da Fundação Casa de Rio Barbosa (org.). A crônica. O Gênero, sua fixação e suas transformações no Brasil. Campinas: Editora da UNICAMP; Rio de Janeiro: Fundação Casa Rui Barbosa, 1992. (Vol. 5).

A vida ao rés do chão. In.: Para gostar de ler: crônicas. São Paulo: Ática, 1980

CANO, Jéferson. Introdução. In: MACEDO, Joaquim Manuel de. Labirinto. Campinas: Mercado de Letras, Cecult; São Paulo: Fapesp, 2004.

CARVALHO, José Murilo de. A construção da ordem: elite política imperial; Teatro de sombras: a política imperial. Rio de Janeiro: Civilização Brasileira, 2010.

Cidadania no Brasil. O longo Caminho. $3^{\text {a }}$ ed. Rio de Janeiro: Civilização

Brasileira, 2001.

CHALHOUB, Sidney. Trabalho, lar e botequim: o cotidiano dos trabalhadores no Rio de Janeiro da belle époque. Campinas, SP: Editora da Unicamp, 2001.

; NEVES; Margarida S.; PEREIRA, Leonardo A. M. (orgs.) História em cousas miúdas: capítulos de História Social da crônica no Brasil. Campinas, Ed. da Unicamp, 2005.

COUTINHO, Afrânio. Ensaio e crônica. In.: A literatura no Brasil (vol. VI): relações e perspectivas. São Paulo: Global, 2008.

DANTAS, Vinícius. Bibliografia de Antonio Candido. São Paulo: Duas Cidades. Ed. 34, 2002. (Coleção Espírito Crítico)

ENGELS, Friedrich. Do Socialismo utópico ao socialismo científico. 2.ed. São Paulo: Editora Instituto José Luís e Rosa Sandermann, 2008.

GUIMARÃES, Hélio de Seixas. Os Leitores de Machado de Assis: o romance machadiano e o público de literatura no século 19. São Paulo: Nankin: EDUSP, 2004.

HABERMAS, Jürgen. Mudança estrutural da esfera pública: investigações quanto a uma categoria da sociedade burguesa. Tradução Flávio R. Kothe. Rio de Janeiro: Tempo Brasileiro, 2003.

HOLANDA, Sergio Buarque de (org.). Historia Geral da Civilização Brasileira. $7^{\mathrm{a}}$ edição. 5 vol. Rio de Janeiro: Bertrand Brasil, 2008. 


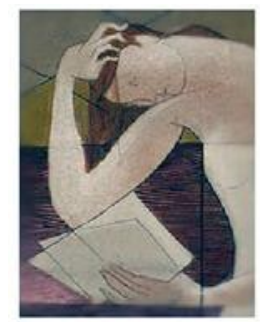

Raízes do Brasil. In.: SANTIAGO, Silviano (org.). Intérpretes do Brasil, volume 3. Rio de Janeiro: Nova Aguilar, 2002.

KONDER, Leandro. A questão da ideologia em Marx. In.: A questão da ideologia. São Paulo: Companhia das Letras, 2002.

LÊNIN, Vladimir Ilitch. O estado e a revolução: O que ensina o marxismo sobre o Estado e o papel do proletariado na revolução. São Paulo: Editora Expressão Popular, 2010.

MARX, Karl e ENGELS, Friedrich. Manifesto do Partido Comunista. São Paulo: Companhia das Letras, 2012.

A ideologia alemã: crítica da mais recente filosofia alemã em seus

representantes Fuerbach, B. Bauer e Stimer, e do socialism alemão em seus diferentes profetas (1845-1846). São Paulo: Boitempo Editorial, 2007.

MEYER, Marlyse. Voláteis e versáteis: de variedades e folhetins se faz a chronica. In.: MEYER, Marlyse. As mil faces de um herói canalha. Rio de Janeiro: Editora da UERJ, 1998.

MORETTI, Franco. Signos da modernidade: ensaios sobre a sociologia das formas literárias. Rio de Janeiro: Civilização Brasileira, 2007.

Conjeturas sobre a literatura mundial. Novos Estudos, CEBRAP, n. 58, nov. 2000, p.173-181.

OLIVEIRA, Francisco de. Jeitinho e jeitão: uma tentativa de interpretação do caráter brasileiro. In.: Revista Piauí, no 73, out. 2012. Disponível em:

http://piaui.folha.uol.com.br/materia/jeitinho-e-jeitao/. Acesso: 05 de dezembro de 2012.

OTSUKA, Edu Teruki. Espírito rixoso: para uma reinterpretação das Memórias de um sargento de milícias. Revista do Instituto de Estudos Brasileiros, v. 44, p. 105-124, 2007.

Divagação sobre a crônica (mimeo).

SÁ, Jorge de. A crônica. São Paulo: Ática, 1987.

SANSEVERINO, Antonio Marcos Vieira. Crônica e cotidiano no final do império: Machado de Assis e a série "Balas de estalo". Projeto apresentado para fins de avaliação e de registro no Sistema de Pesquisa da Universidade Federal do Rio Grande do Sul. Coordenador do Projeto Prof. Dr. Antônio Marcos Vieira Sanseverino Porto Alegre, agosto de 2008 .

SCHWARZ, Roberto. Pressupostos, salvo engano, da "Dialética da malandragem". In.: . Que horas são? Ensaios. São Paulo: Companhia das Letras, 2006. 


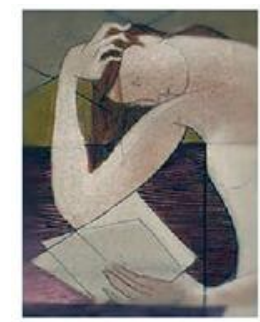

Nau Literáría

crítica e teoria da literatura em língua portuguesa PPG-LET UFRGS ISSN 1981-4526

https://seer.ufrgs.br/NauLiteraria

Vol. 16, n. 22019

Dossiê Antonio Candido

STARLING, Heloísa M. Murgel. República das ruas: imaginação literária e republicanismo no Brasil. In.: ZILBERMAN, Regina (org.). Guimarães Rosa e Machado de Assis: da criação artística à interpretação literária. 1ed. Erechim: Edelbra, 2008, v. 1. 